\title{
Binge eating behavior in a sample of Lebanese Adolescents: Correlates and Binge Eating Scale validation
}

Anthony Mina ${ }^{1 \dagger}$, Souheil Hallit ${ }^{1,2^{*}}$ (D), Radoslaw Rogoza ${ }^{3}$, Sahar Obeid ${ }^{4 \dagger}$ and Michel Soufia ${ }^{*^{*}}$

\begin{abstract}
Background: Binge eating disorder is a common eating disorder among the adolescent population. The available literature in the Middle East in general, and Lebanon specifically, is relatively scarce and/or outdated. The objectives of this study were to (1) validate the Binge Eating Scale (BES) for use in Lebanese adolescents, and (2) assess correlates of binge eating behavior among this population.

Methods: A cross-sectional study conducted between May and June 2020, enrolling 555 adolescents between the ages of 15-18 years old from all Lebanese governorates. The Binge Eating Scale was used to screen for the presence/ absence of binge eating.
\end{abstract}

Results: A confirmatory factor analysis revealed that the one-factorial model fits the data best. The results of a linear regression, taking the binge eating score as the dependent variable, showed that higher body dissatisfaction, more alcohol use disorder, higher depression, vomiting to lose weight and starving to lose weight were significantly associated with more binge eating. Higher self-esteem was significantly associated with less binge eating.

Conclusion: The Arabic Version of the BES scale seems to be a reliable tool to be used in Lebanese adolescents for the assessment of binge eating. More body dissatisfaction, lower self-esteem, increased depressive symptoms were associated with more binge eating. We hope this tool will be a reliable one to be used in epidemiological studies and research about eating behaviors/disorders.

Plain English summary: The results showed that higher body dissatisfaction, higher depression, vomiting to lose weight and starving to lose weight were significantly associated with more binge eating. Our study also showed that the Binge Eating Scale is an adapted and validated tool to be used among Lebanese adolescents for the assessment of binge eating. We hope that the study results will help clinicians in the screening and management of Binge Eating behaviors among Lebanese adolescents.

Keywords: Binge Eating, Adolescents, Body dissatisfaction, Self-esteem, Depression

*Correspondence: souheilhallit@hotmail.com; michel_soufia@hotmail.com ${ }^{\dagger}$ Anthony Mina and Souheil Hallit are first coauthors

†Sahar Obeid and Michel Soufia are last coauthors

${ }^{1}$ Faculty of Medicine and Medical Sciences, Holy Spirit University of Kaslik (USEK), Jounieh, Lebanon

Full list of author information is available at the end of the article

\section{Background}

Binge eating (BE), a manifestation of disordered eating, is defined as an uncontrolled consumption of large of quantities of food [1]. This behavior could be observed in binge eating disorder (BED), bulimia nervosa $(\mathrm{BN})$ and anorexia nervosa (AN) (binge/purge subtype) [2, 3]. In the case of BED, the individual will suffer from multiple $\mathrm{BE}$ episodes, in association with feelings of distress, guilt original author(s) and the source, provide a link to the Creative Commons licence, and indicate if changes were made. The images or other third party material in this article are included in the article's Creative Commons licence, unless indicated otherwise in a credit line to the material. If material is not included in the article's Creative Commons licence and your intended use is not permitted by statutory regulation or exceeds the permitted use, you will need to obtain permission directly from the copyright holder. To view a copy of this licence, visit http://creativecommons.org/licenses/by/4.0/. The Creative Commons Public Domain Dedication waiver (http://creativeco mmons.org/publicdomain/zero/1.0/) applies to the data made available in this article, unless otherwise stated in a credit line to the data. 
and loss of control sensation during the episodes [4]. This eating disorder is characterized by at least one episode of BE per week for at least 3 months. Unlike other eating disorders such as bulimia nervosa, no compensating behaviors to lose weight are identified, such as purging, over exercising, going on a severe diet or taking medications (diuretics or laxatives) [4]. BED is a common eating disorder among young adolescents, with a lifetime prevalence of $1.6 \%$, followed by $\mathrm{BN}(0.9 \%)$ and $\mathrm{AN}(0.3 \%)$, and is prominent in girls [2].

The available literature related to $\mathrm{BE}$ in the Middle East in general and Lebanon specifically, is relatively scarce and/or outdated. When examining the Middle East, the risk of having an episode of $\mathrm{BE}$ was highest among Egyptian $(1990, N=218)$ [5] and Kuwaiti populations (2013, $N=320$, over $80 \%$ reported BE) [6]. However, those studies are relatively old and include a relatively small sample of young adults [7]. Other studies showed a BE rate of $4.9 \%$ among a Jordanian young adult population [7], while another study indicated a moderate reporting of $\mathrm{BE}$ varying between 16.9 and $24.9 \%$, with severe $\mathrm{BE}$ between 6.4 and $13.2 \%$ among young UAE adults [8].

When focusing on Arabic-speaking adolescent populations, reporting of BE; rates varied between 16.9 and $33 \%$ in two different samples of Jordanian adolescents $[9,10]$, while it was $14 \%$ among adolescents in Oman [11]. To the best of our knowledge, no study has evaluated BE in Lebanese adolescents to this date.

A study among Lebanese adults showed an association of BED with several already known BED correlates such as body dissatisfaction, anxiety, depression, sexual abuse, family history of BE and low self-esteem level [12].

The presence of $\mathrm{BE}$ in adolescents can be mostly accredited to major eating disorders such as BED and Bulimia, both prevalent in adolescents [13]. Body dissatisfaction (BD) is one of the strongest influencing factors of $\mathrm{BE}$ [14]. Literature clearly shows that a reduced body dissatisfaction level in an adolescent will lead to better outcomes in eating disorders treatment [15]. Better control of weight and BE episodes were observed in adolescents as well as a better control of self-esteem levels, anxiety, and depression among these individuals [15]. The role of self-esteem is observed in the development of healthy personality characteristics development [16]. Alongside BD, self-esteem levels also predicted outcome of treatment and a higher self-esteem level further reduced eating disorders development and manifestations in adolescents [17]. Other BE correlates found in the literature include smoking and problematic alcohol consumption. Although waterpipe smoking is prominent in Lebanese adolescents, an approach to underline its correlation to eating disorder and BE specifically is lacking [18].

\section{Measuring Binge Eating (BE) behavior}

The gold standard to assess $\mathrm{BE}$ behavior is by interview, using tools such as Eating Disorder Examination. However, it is time consuming and requires a trained clinician, raising the need for a more efficient form of assessment [3]. The development of self-administered, straightforward questionnaires allow a good assessment of individual's eating disorder symptomatology [3]. Indeed, some behaviors could be easier to assess by the individual himself rather than a secondary party [19]. Moreover, it offers for adolescents the anonymity of their answers, possibly generating more truthful responses among this type of population, in fears of judgment by peers or adults [3]. The nature of $\mathrm{BE}$ and the associated loss of control feeling, could be better assessed by validated self-report scales such as the BES [3]. The Binge Eating Scale (BES) covers multiple aspects of eating habits including but not limited to feelings, cognitions and behaviors [20]. It also assesses the impact of environment factors on weight control (such as media pressure, social isolation, and weighing oneself daily) [20].

In a recent systematic review about self-report measures used in the assessment of BE symptoms, the BES showed good internal consistency, an adequate agreement in terms of reproducibility, and very clear floor and ceiling effect, as well as being easy to interpret and differentiate multiple relevant groups within the scale. [3] It was first created for the purpose of detecting BE behaviors in overweight and obese people [20]; it has been later on successfully validated among various ethnic and cultural groups across the world [21-24]. In obese and bariatric candidates, this scale has shown to have great specificity and sensitivity in distinguishing binge from non-binge eaters, in comparison to results obtained from reliable, semi-structured interviews [3]. Additionally, this study has shown high value in non-clinical settings and is used as a treatment outcome assessment tool in some populations [24]. It is worth noting that this scale has been previously validated within the Lebanese adult population and has been found to have good psychometric properties [25]; the results indicated a two-factor model that has a good internal consistency (Cronbach's alpha $=0.86$ ) [25].

While $\mathrm{BE}$ is seen in various disorders, it is rather one of many important manifestations of eating disorders, making its measurement a very important clinical assessment. Thus, the objectives of this study were to (1) validate the BES for use in Lebanese adolescents, and (2) assess the correlates of BE behavior, most importantly self-esteem, body dissatisfaction, anxiety, cigarette and waterpipe dependence, alcohol use disorder, and depression. In terms of correlates, we would assume that higher body dissatisfaction, anxiety, depression, nicotine 
dependence and problematic alcohol consumption and lower self-esteem would be associated with more BE.

\section{Methods}

\section{Study design and participants}

This cross-sectional study involved a sample of Lebanese adolescents with age ranging from 15 to 18 years old currently residing in Lebanon's governorates (Beirut, North, South, Bekaa, Mount Lebanon). Excluded from this sample were participants outside the age interval $(<15$ years and $>18$ years) as well students of Lebanese origin living outside the Lebanese territory. The same methodology is described in previous papers from the same project [26, 27].

\section{Procedure}

The coronavirus pandemic challenged the proper execution of the study due to nationwide lockdown, curfews, required social distancing, and schools' closing. In response to this new situation, a transition of the study data collection towards an online available questionnaire, was deemed necessary. A "Google Forms" link was therefore, created (https://forms.gle/7J8vMyAyanUugJpf8). Prior to proceeding with the data collection, a pilot study was conducted on 20 students, to assess the duration and technical feasibility as well as fixing misconceptions or misunderstandings related to the questions. The data collection was carried out between May and June 2020 using a snowball technique, delivering a message containing a brief description of our study and the available study link. Later, initial participants were asked to recruit other participants they know from the same age and from all Lebanese governorates.

\section{Minimal sample size calculation}

According to the G-power software and based on an effect size $\mathrm{f}^{2}=2 \%$, an alpha error of $5 \%$, a power of $80 \%$, and taking into consideration 20 factors to be entered in the multivariable analysis, the results showed that a minimum number of 395 was needed to have enough statistical power.

\section{Forward and back translation}

The forward and backward translation method was used on the Rosenberg Self Esteem Scale (RSES) and Eating Disorders Inventory-2 Body Dissatisfaction Subscale (EDI-2-BD) scales in the questionnaire, following international guidelines $[28,29]$. The forward translation was done by a clinical psychologist. A psychiatrist performed the back translation. The back-translated English questionnaire was subsequently compared to the original English one, by a committee composed by two psychologists, one psychiatrist and one pharmacist, aiming to discern discrepancies and solve any inconsistencies between the two versions. Revisions of problematic questions were communicated with both translators involved for version updating. The process of forward-back translation was repeated until all ambiguities disappeared.

\section{Measures}

The Arabic questionnaire contained an introductory page explaining the purpose of this study, a confirmation of the anonymity of the participants and a statement about the non-traceability of the responses whatsoever. Furthermore, a consent form, requiring the approval of the parents, was required before proceeding to the questions. The student had the choice to accept or refuse participation, with no financial compensation given.

The survey covered in its first part the sociodemographic factors such as age, gender, governorate, family monthly income, and the house crowding index ( $\mathrm{HCI})$, which reflects the socioeconomic status; the $\mathrm{HCI}$ is calculated by dividing the number of persons living in the house by the number of rooms excluding the kitchen and bathrooms. A higher HCI score reflects a lower socioeconomic status [30].

In the next section, it covered questions regarding eating habits of the participants that were identified from previous articles [31, 32]: "Do you follow a diet to lose weight?", “Do you exercise to lose weight?", "Do you take medication to lose weight?, "Do you vomit to lose weight?", “Do you starve yourself to lose weight?", “Do you weight yourself daily?", "Do you experience social isolation", "Do you have a family history of eating disorders?", "Do you feel pressured by the media to lose weight?" Those questions had a yes/no type of answer.

The final section of the questionnaire contained the internationally validated scales:

\section{Binge Eating Scale (BES)}

Validated in Lebanon [25], this scale is composed of 16 items, computing a total score from 0 to 46 [20]. People scoring $<17$ were classified as having no to mild $\mathrm{BE}$, whereas those who had a score between 18 and 26 and 27 and above were classified as having moderate and severe $\mathrm{BE}$ respectively.

\section{Rosenberg Self Esteem Scale (RSES)}

It is a self-reported, 10-item tool with the target of assessing one's global self-worth and self-esteem [33]. Items answers vary from strongly disagree to strongly agree. Higher scores indicate higher self-esteem. 


\section{Eating Disorders Inventory-2 Body Dissatisfaction Subscale (EDI-2-BD)}

This subscale assesses the overall body image and specific body parts satisfaction [34]. It contains 9 items questions; the higher the score, the more severe the body dissatisfaction.

\section{Patient Health Questionnaire (PHQ-9)}

Validated in Lebanon [35], the PHQ-9 [36] is a 9-item instrument developed for screening for the presence of depressive symptoms. Each item is scored on a fourpoint Likert scale, ranging from 0 (not at all, several days, more than half the days) to 3 (nearly every day). Higher scores reflect more depressive symptoms.

\section{Hamilton Anxiety Rating Scale (HAM-A)}

The HAM-A scale is 14-item questionnaire, with the target of assessing both psychiatric based anxiety and somatic based anxiety [37]. Higher scores indicate more severe anxiety. This scale has been previously validated among Lebanese adults [31] and among the adolescent population [38].

\section{Alcohol Disorder Identification Scale (AUDIT)}

This scale, validated in Lebanese adolescents [39], was constructed by the World Health Organization (WHO) [40] with the purpose of profiling alcohol consumption, drinking patterns and drinking related problems. Due to the nature of this study, a self-reported version of this scale was administered, with a score of 8 or more pointing towards the presence of alcohol use disorder.

\section{Lebanese Waterpipe Identification Scale (LWDS-11)}

The LWDS-11 is composed of 11 items, scored on a fourpoint Likert scale [41, 42]. Higher scores reflect more waterpipe dependence.

\section{Fagerstrom Nicotine Dependence Scale (FTND)}

The Fagerstrom nicotine dependence scale [43], validated in Lebanon [44], is a valuable instrument containing 6 items in relation with physical dependence to nicotine assessment. Higher scores reflect higher nicotine dependence.

\section{Statistical analyses}

To assess the internal structure of the BES, we used the confirmatory factor analysis (CFA), which was carried out in Mplus v. 7.2. To evaluate the model fit, we relied on standard recommendations, that is the root mean square error of approximation (RMSEA) statistic and the comparative fit index (CFI) [45]. RMSEA values $\leq 0.06$ or CFI values $>0.90$ indicate a good-fitting model [45]. The CFA was based on polychoric correlation matrix with Weighted Least Squares with Means and Variances Adjusted estimator (i.e., Mplus WLSMV). We tested two models, present within the literature, that is one-factorial model where a single latent factor is loaded by all items, and a two-factor model, representing behavioral and emotional/cognitive aspects of binge eating [24].

Student $t$ and ANOVA tests were used to compare two and three or more means respectively. Pearson correlation test was used to correlate two continuous variables. A linear regression was conducted using the enter method, taking the binge eating score as the dependent variable and all variables that showed a $p<0.20$ in the bivariate analysis, as independent variables. $P<0.05$ was considered significant.

\section{Results}

The Cronbach's alpha values for the scales used in this study were as follows: BES (0.835), RSES (0.768), EDI2-BD (0.82), PHQ-9 (0.837), HAM-A (0.893), AUDIT (0.888), LWDS (0.622), and FTND (0.632).

The mean age of the participants was $16.67 \pm 1.00$ years, with $75.7 \%$ females. The mean household crowding index was $0.95 \pm 0.50$. More details about the students can be found in Table 1. The mean BES score was $5.07 \pm 4.96$ $($ median $=4$; minimum $=0$; maximum $=27$ ). The results also showed that 537 (96.8\%) adolescents had no or mild binge eating (scores of 17 or less), 17 (3.1\%) had possible binge eating (scores between 18 and 26) and $1(0.2 \%)$ adolescent scored 27 on the BES scale and was classified as having binge eating.

\section{Validation of the BES: confirmatory factor analysis}

Results of the CFA revealed that both tested models, that is, one-factorial $\left(\chi_{(104)}^{2}=213.23 ; p<0.001\right.$; $\mathrm{CFI}=0.964 ; \mathrm{RMSEA}=0.041[0.033,0.049])$ and twofactorial $\quad\left(x^{2}{ }_{(102)}=209.16 ; \quad p<0.001 ; \quad\right.$ CFI $=0.965$; RMSEA $=0.041[0.033,0.049])$ fitted the data well. The difference in fit indices between these models was however negligible. The $\chi^{2}$ test for nested model claimed this difference to be non-significant $\left(\chi_{(2)}^{2}=4.07 ; p<0.131\right)$. The behavioral and emotional/cognitive latent factors were furthermore correlated $(\rho=0.95 ; p<0.001)$ to the extent to which it was almost impossible to differentiate between them. Thus, the one-factorial structure of the $\mathrm{BES}$ in adolescent sample seems to be preferable. The standardized factor loadings for this model are given in the Table 2.

\section{Correlates of BES \\ Bivariate analysis}

Higher body dissatisfaction, alcohol use disorder, anxiety and depression were significantly associated with more binge eating, whereas higher self-esteem was 
Table 1 Sociodemographic and other characteristics of the participants ( $N=555)$

\begin{tabular}{ll}
\hline Variable & N (\%) \\
\hline Gender & $135(24.3 \%)$ \\
Male & $420(75.7 \%)$ \\
Female & \\
District & $70(12.6 \%)$ \\
Beirut & $355(64.0 \%)$ \\
Mount Lebanon & $84(15.1 \%)$ \\
North & $16(2.9 \%)$ \\
South & $30(5.4 \%)$ \\
Bekaa & $\mathbf{M e a n} \pm \mathbf{S D}$ \\
\hline & $16.67 \pm 1.00$ \\
\hline Age (in years) & $22.31 \pm 4.07$ \\
Body Mass Index (kg/m $\left.{ }^{2}\right)$ & $0.95 \pm 0.50$ \\
Household crowding index & $19(3.4 \%)$ \\
Cigarette smokers (yes) & $47(8.5 \%)$ \\
Waterpipe smokers (yes) & $549(98.9 \%)$ \\
Alcohol drinking (yes) & \\
\hline
\end{tabular}

Table 2 Standardized factor loadings of the one-factorial measurement model

\begin{tabular}{ll}
\hline Item & Factor loading \\
\hline 1. Manner of eating food & .54 \\
2. Degree of loss of control while binge eating & .36 \\
3. Degree of loss of control while eating & .80 \\
4. Food trigger: boredom & .53 \\
5. Impulsive eating & .66 \\
6. Guilt feeling after eating & .67 \\
7. Dieting/Feasting balance & .79 \\
8. Quantity of food digested in one setting & .51 \\
9. Calories balance and control & .60 \\
10. Eating episodes control and balance & .72 \\
11. Stopping an episode of binge eating & .77 \\
12. Social alterations of eating & .72 \\
13. Numbers and planning of meals & .57 \\
14. Obsession and guilt over binge eating & .71 \\
15. Control of food and eating over thoughts and & .74 \\
behaviors & \\
16. Recognition of hunger & .59 \\
\hline
\end{tabular}

significantly associated with less binge eating (Table 3). Females compared to males, those who vomit or take medications or starve themselves to lose weight, those who weigh themselves daily and those who feel pressured by media to lose weight had significantly more binge eating (Table 4).
Table 3 Bivariate analysis of continuous variables associated with the binge eating score

\begin{tabular}{lc}
\hline Variable & $\begin{array}{c}\text { Correlation } \\
\text { coefficients }\end{array}$ \\
\hline Body dissatisfaction & $0.35^{\mathrm{a}}$ \\
Self-esteem & $-0.36^{\mathrm{a}}$ \\
Cigarette dependence & 0.22 \\
Waterpipe dependence & 0.07 \\
Alcohol use disorder (AUDIT score) & $0.29^{\mathrm{a}}$ \\
Anxiety & $0.26^{\mathrm{a}}$ \\
Depression & $0.33^{\mathrm{a}}$ \\
Age & -0.06 \\
House crowding index & -0.01 \\
Body Mass Index & 0.10 \\
\hline
\end{tabular}

a $p<0.001$; numbers displayed in the table represent correlation coefficients obtained from the Pearson correlation test. Numbers without a sign next to them represent non-significant associations

\section{Multivariable analysis}

The results of a linear regression, taking the binge eating score as the dependent variable, showed that higher body dissatisfaction (Beta $=0.16)$, higher depression $($ Beta $=0.21)$, alcohol use disorder $($ Beta $=0.24)$, vomiting to lose weight $($ Beta $=1.71)$ and starving to lose weight $($ Beta $=1.48)$ were significantly associated with more binge eating. Higher self-esteem (Beta $=-0.12$ ) was significantly with less binge eating (Table 5 ). 
Table 4 Bivariate analysis of categorical variables associated with the binge eating score

\begin{tabular}{|c|c|c|}
\hline Variable & $\begin{array}{l}\text { Mean binge eating } \\
\text { score }\end{array}$ & $p$ \\
\hline Gender & & $<0.001$ \\
\hline Male & $3.78 \pm 4.07$ & \\
\hline Female & $5.68 \pm 5.40$ & \\
\hline Following a diet to lose weight & & 0.262 \\
\hline $\mathrm{No}(N=377)$ & $3.99 \pm 4.13$ & \\
\hline Yes $(N=237)$ & $5.88 \pm 5.69$ & \\
\hline Exercising to lose weight & & 0.262 \\
\hline $\mathrm{No}(N=197)$ & $4.08 \pm 4.72$ & \\
\hline Yes $(N=417)$ & $5.07 \pm 4.89$ & \\
\hline Vomiting to lose weight & & 0.003 \\
\hline $\mathrm{No}(N=535)$ & $4.15 \pm 4.31$ & \\
\hline Yes $(N=79)$ & $7.67 \pm 6.39$ & \\
\hline Taking medications to lose weight & & 0.008 \\
\hline $\mathrm{No}(N=560)$ & $4.31 \pm 4.52$ & \\
\hline Yes $(N=54)$ & $7.38 \pm 6.17$ & \\
\hline Starving to lose weight & & 0.009 \\
\hline No $(N=462)$ & $3.94 \pm 4.05$ & \\
\hline Yes $(N=152)$ & $6.93 \pm 6.18$ & \\
\hline Weighing yourself daily & & 0.001 \\
\hline No $(N=458)$ & $4.15 \pm 4.56$ & \\
\hline Yes $(N=156)$ & $6.32 \pm 5.37$ & \\
\hline Experienced social isolation & & 0.115 \\
\hline No $(N=419)$ & $4.34 \pm 4.68$ & \\
\hline Yes $(N=195)$ & $5.46 \pm 5.13$ & \\
\hline Family history of eating disorders & & 0.220 \\
\hline No $(N=419)$ & $4.38 \pm 4.60$ & \\
\hline Yes $(N=195)$ & $5.49 \pm 5.37$ & \\
\hline Pressured by media to lose weight & & $<0.001$ \\
\hline $\mathrm{No}(N=447)$ & $3.68 \pm 3.94$ & \\
\hline Yes $(N=167)$ & $6.86 \pm 5.82$ & \\
\hline
\end{tabular}

\section{Discussion}

The results of this study showed that higher BE was associated with higher levels of $\mathrm{BD}$, anxiety/depression as well lower levels of self-esteem, confirming our hypothesis. Moreover, problematic alcoholism was associated with an increase in BE, in agreement with a French adolescents cross sectional study. However, no significant association was found in our sample between $\mathrm{BE}$ and waterpipe/cigarette smoking. This result could be due to the small number of smokers in our sample.

\section{Validation of the BES}

The BES has been repetitively validated across different ethnic and cultural groups with continuous consistent and strong results [21, 23, 24]. To our knowledge, no previous attempt has been made towards validating this scale within an adolescent population, and specifically an Arabic speaking one. The initial psychometric properties of the scale suggest a one-factor solution, similar to the results observed in Spanish [24] and French [21] populations, but different from the results obtained in Malay [46] and Lebanese [25] adults (two-factor solution). The internal consistency of the scale in this study (Cronbach's alpha $=0.835$ ) was similar to the one obtained in the original scale [20] and previous validations in various populations (0.85 in Iran [22], 0.862 in Lebanon [25] and 0.93 in France [21]). Although both factor and confirmatory analysis are satisfying, more psychometric properties of the BES scale (convergent validity with other scales to assess eating disorders (e.g. Eating Attitude Test, testretest reliability) are still lacking. The survey did not ask about self-reported binge eating (yes/no type of answer). Future studies should focus on assessing more psychometric properties of the BES by collecting data about more closely related measures to the scale and also examine the scale's reliability within this population in terms

Table 5 Multivariable analysis: linear regression (using the enter model) taking the binge eating score as the dependent variable

\begin{tabular}{|c|c|c|c|c|}
\hline Variable & Beta & $\beta$ & $p$ & $95 \% \mathrm{Cl}$ \\
\hline Body dissatisfaction & 0.16 & 0.21 & $<0.001$ & $0.10-0.22$ \\
\hline Self-esteem & -0.12 & -0.14 & 0.001 & -0.19 to -0.05 \\
\hline Depression & 0.19 & 0.21 & $<0.001$ & $0.10-0.28$ \\
\hline Anxiety & 0.01 & 0.02 & 0.730 & -0.03 to 0.05 \\
\hline Alcohol use disorder (AUDIT score) & 0.24 & 0.21 & $<0.001$ & $0.16-0.31$ \\
\hline Gender (females vs males*) & 0.66 & 0.06 & 0.112 & -0.16 to 1.48 \\
\hline Vomited to lose weight (yes vs no*) & 1.71 & 0.12 & 0.005 & $0.51-2.92$ \\
\hline Medications to lose weight (yes vs no*) & 0.57 & 0.03 & 0.423 & -0.83 to 1.97 \\
\hline Weigh yourself daily (yes vs no*) & -0.08 & -0.01 & 0.850 & -0.95 to 0.78 \\
\hline Pressured by media to change weight (yes vs no*) & 0.32 & 0.03 & 0.430 & -0.48 to 1.12 \\
\hline Starve yourself to lose weight (yes vs no*) & 1.48 & 0.13 & 0.001 & $0.57-2.38$ \\
\hline Experienced social isolation (yes vs no*) & -0.34 & -0.03 & 0.376 & -1.11 to 0.42 \\
\hline
\end{tabular}


of test-retest. Consequently, the Arabic version of the Binge Eating Scale (BES) seems to be a reliable tool for screening for the presence of binge eating among Lebanese adolescents.

Concerning the rate of binge eating, the results showed that $17(2.8 \%)$ students had possible binge eating and 1 $(0.2 \%)$ adolescent had binge eating. A study with a similar sample size and average age of participants reported a prevalence of $1 \%$ of $\mathrm{BE}$ among participants [47]. On the other hand, a study assessing BE among 2000 adolescents in Mumbai reported a high prevalence of binge eating behavior $(50 \%)$, with $36 \%$ reporting severe binge eating [48]. However, these estimates need to be interpreted with caution. We reported $1 \%$ of $\mathrm{BE}$ according to our sample and $50 \%$ of $\mathrm{BE}$ according to its scores in the Mumbai study population [48]; this might be due to the convenient sample collected in the study (because of the pandemic and restrictions of face-to-face meetings) as well as gender [49] and cultural [50] differences regarding attitudes towards eating. Future studies should resolve this problem by recruiting a random sample of adolescents.

\section{Correlates of binge eating}

Higher depression and body dissatisfaction were significantly associated with more BE, in line with previous studies in adolescents [51-53]; this association with $\mathrm{BE}$ could be partially explained by the severity of BD in the individual, which was found to severely affect and predict depression [54]. In addition, this association could be the result of a reciprocal relationship between depression and $\mathrm{BE}$ with one factor being the cause or result of the other $[55,56]$, while some studies suggested the possibility of them sharing common risk factors $[57,58]$. For example, feeling worthless could be a shared basis for the development and maintenance of depression, and the root for the perceived sense of shame with regard to body self-evaluation [55].

Higher $\mathrm{BD}$ was associated with more $\mathrm{BE}$, consistent with various other studies in different populations $[2,25]$. In a pathway model established by Tuschen Cafier and Hilbert [59], external and internal stressors triggering $\mathrm{BE}$ were highlighted (low self-esteem, exposure to food, impulsive behavior, tensions). Moreover, weight management and body image dissatisfaction were considered as major risk factors for the development, evolution and treatment of binge eating [59]. Body dissatisfaction is a lifelong predictor of eating disorders $[27,60,61]$ and specifically binge eating $[62,63]$.

Our results indicated that lower self-esteem was associated with more binge eating behaviors among adolescents, in line with other studies [64-67]. Self-esteem could be either a cause to or a consequence of body dissatisfaction and body image disturbance $[54,68]$. Low self-esteem was found to be a source of negative emotions and negative image towards the self, in addition to increasing the risk of eating disorders [69]. Indeed, global self-esteem is representative of inner evaluation towards oneself and reflects negative affect, with eating disorder patients having a level of self-esteem regulation based on their perceived unsatisfactory weight and shape acceptance [70].

Vomiting to lose weight was associated with more BE behaviors, a condition found in certain eating disorders such as BN and subtypes of AN but not binge eating disorder [4]. The presence of vomiting to lose weight has long been described in BE pathology [71, 72], as part of weight controlling behaviors associated with disordered eating. Studies have shown that in adolescents, vomiting to lose weight is highly prevalent as weight control behaviors [73-75].

Our analysis revealed that starving to lose weight was associated with more binge eating behavior, in line with previous findings that showed that a purposeful decrease in calories/meals intake was found in various eating disorders [76]. Starvation to lose weight is a radical form of weight loss maneuver, part of dietary restraint, and was found to be a maintenance factor of binge eating behaviors in various other studies $[65,77]$.

\section{Clinical implications}

The results described above, although acknowledged previously in the literature, reconfirm the underlying psychiatric burden of BE in Lebanese adolescents. The establishment of these relationships broaden the profile of a person who engages in binge eating and may offer a better management and treatment of any underlying conditions that could be present. These results will allow us gain a better perspective about $\mathrm{BE}$ among Lebanese adolescents, guiding future studies in this field. The results also emphasize on the lower rate of $\mathrm{BE}$ in the Lebanese society compared to Western cultures. Binge eating behaviors, if present within the adolescent population in Lebanon, are mainly driven by an elevated body dissatisfaction level, depression, and lower self-esteem. This underlines the need to address eating disorders more frequently during adolescence and advise various society members such as teachers, parents, and health care providers on the issue. Additionally, awareness among adolescents should be initiated since eating disorders pose some serious health adverse effects on the body and mind.

\section{Limitations and strengths}

This research used a cross-sectional study design and therefore cannot underline causalities and relationships 
between the above studied variables. The scales used for evaluation of some research parameters were not fully validated in the Arabic language and are used for screening purposes of disordered psychiatric behaviors; therefore, they could not confirm the clinical diagnosis and cannot replace the need for a clinical interview. The snowball sampling technique and respondent driven strategies used for achieving the sample size, alongside external factors such as the ongoing COVID19 pandemic and its resulting nationwide lockdown presented a challenge for proper data collection. The use of this technique could lead to a source of information bias mainly in relation of understanding the questions, accurately estimating symptoms, resulting in possible inaccuracy. A disequilibrium in our sample was a numerical superiority in female respondents compared to their male counterparts and in terms of the higher percentage of alcohol drinking and low percentages of cigarette and waterpipe smoking. Furthermore, the results of this study may not be representative of the entire population since respondents had a high school level of education. The COVID-19 pandemic and its consequent lockdowns were associated with higher mental health issues (depression, anxiety, stress, obsession, etc.) among the Lebanese population [78], as well as more disordered eating [79]. The economic crisis, lack of clean water, recurrent power failure, and waste mismanagement and Syrian refugees immigration to Lebanon $[80,81]$ have also impacted psychological behaviors, possibly affecting our findings. Finally, a residual confounding bias is also possible since not all factors associated with binge eating were taken into consideration in this study. On another hand, this study is unique in the Arabic region (and the first in Lebanon) in addressing binge eating disorders in an Arabic adolescent population, with a large sample size distributed across major districts. It can be useful as preliminary template to further develop future studies.

\section{Conclusion}

This study has acknowledged some correlates of $\mathrm{BE}$ among adolescents. Additionally, the validation of the Arabic BES scale is a crucial contribution to the relatively scarce published literature available regarding binge eating behavior and represents a step forward toward characterizing BE's presence in the region, a topic poorly addressed in the Arabic community. Finally, the study results offer a promising perspective into continuation of research; possibly with an interview-based approach, with the help of clinicians in order to better tailor screening and management of Binge Eating behaviors in Lebanese adolescents.

\section{Abbreviations}

BES: Binge Eating Scale; BE: Binge eating; BED: Binge eating disorder; BN: Bulimia nervosa; AN: Anorexia nervosa; $\mathrm{HCl}$ : Household crowding index; RSES: Rosenberg Self Esteem Scale; EDI-2-BD: Eating Disorders Inventory-2 Body Dissatisfaction Subscale; PHQ-9: Patient Health Questionnaire; HAM-A: Hamilton Anxiety Rating Scale; AUDIT: Alcohol Disorder Identification Scale; WHO: World Health Organization; LWDS-11: Lebanese Waterpipe Identification Scale; CFA: Confirmatory factor analysis; CFI: Comparative fit index; WLSMV: Weighted least squares with means and variances adjusted estimator.

\section{Acknowledgements}

The authors acknowledge all participants who helped them achieve this study, as well as Dr. Mariam Mhanna, Dr. Reine Azzi and Dr. Serena Samaha for their help in the data collection.

\section{Authors' contributions}

AM was responsible for the data collection and entry. MS, SH and SO designed the study; AM drafted the manuscript; SH carried out the analysis and interpreted the results; all authors reviewed the final manuscript and gave their consent.

\section{Funding \\ The work of Radosław Rogoza was supported by the Foundation for Polish Science (FNP).}

\section{Availability of data and materials}

All data generated or analyzed during this study are not publicly available to maintain the privacy of the individuals'identities. The dataset supporting the conclusions is available upon request to the corresponding author.

\section{Declarations}

\section{Ethics approval and consent to participate}

The Ethics and Research Committee of the Psychiatric Hospital of the Cross approved this study protocol (HPC-035-2020). Students were asked to get their parents' consent before filling the survey. All procedures performed in studies involving human participants were in accordance with the ethical standards of the institutional and/or national research committee and with the 1964 Helsinki Declaration and its later amendments or comparable ethical standards.

\section{Consent for publication}

Not applicable.

\section{Competing interests}

The authors declare that they have no competing interests.

\section{Author details}

${ }^{1}$ Faculty of Medicine and Medical Sciences, Holy Spirit University of Kaslik (USEK), Jounieh, Lebanon. ${ }^{2}$ Research Department, Psychiatric Hospital of the Cross, Jal Eddib, Lebanon. ${ }^{3}$ Institute of Psychology, Cardinal Stefan Wyszyński University, Wóycickiego 1/3, 01-938 Warsaw, Poland. ${ }^{4}$ Faculty of Arts and Sciences, Holy Spirit University of Kaslik (USEK), Jounieh, Lebanon.

Received: 19 April 2021 Accepted: 12 October 2021

Published online: 20 October 2021

References

1. Binge Eating Medical Definition / Merriam-Webster Medical Dictionary. Accessed March 17, 2021. https://www.merriam-webster.com/medical/ binge eating

2. Stice E, Gau JM, Rohde P, Shaw H. Risk factors that predict future onset of each DSM-5 eating disorder: predictive specificity in high-risk adolescent females. J Abnorm Psychol. 2017;126(1):38-51. https://doi.org/10.1037/ abn0000219.

3. Burton AL, Abbott MJ, Modini M, Touyz S. Psychometric evaluation of self-report measures of binge-eating symptoms and related 
psychopathology: a systematic review of the literature. Int J Eat Disord. 2016;49(2):123-40. https://doi.org/10.1002/eat.22453.

4. American Psychiatric Association. Diagnostic and statistical manual of mental disorders. 5th ed. American Psychiatric Association; 2013.

5. Binge eating and dietary restraint: a cross-cultural analysis - Dolan - 1991 - International Journal of Eating Disorders - Wiley Online Library. https:// doi.org/10.1002/1098-108X(199105)10:3\%3C345::AID-EAT2260100310\% 3E3.0.CO;2-9. Accessed 14 Aug 2021

6. Musaiger AO, Al-Kandari Fl, Al-Mannai M, et al. Perceived barriers to weight maintenance among university students in Kuwait: the role of gender and obesity. Environ Health Prev Med. 2014;19(3):207. https://doi. org/10.1007/S12199-013-0377-Z.

7. Melisse B, De Beurs E, Van Furth EF. Eating disorders in the Arab world: a literature review. J Eating Disord. 2020. https://doi.org/10.1186/ s40337-020-00336-X.

8. Schulte SJ. Predictors of binge eating in male and female youths in the United Arab Emirates. Appetite. 2016;105:312-9. https://doi.org/10. 1016/j.appet.2016.06.004

9. Mousa TY, Al-Domi HA, Mashal RH, Jibril MA. Eating disturbances among adolescent schoolgirls in Jordan. Appetite. 2010;54(1):196-201. https:// doi.org/10.1016/j.appet.2009.10.008.

10. Mousa TY, Mashal RH, Al-Domi HA, Jibril MA. Body image dissatisfaction among adolescent schoolgirls in Jordan. Body Image. 2010;7(1):46-50. https://doi.org/10.1016/J.BODYIM.2009.10.002.

11. Al-Adawi S, Dorvlo AS, Burke DT, Al-Bahlani S, Martin RG, Al-lsmaily S. Presence and severity of anorexia and bulimia among male and female Omani and non-Omani adolescents. J Am Acad Child Adolesc Psychiatry. 2002;41(9):1124-30. https://doi.org/10.1097/00004583-200209000-00013.

12. Sfeir E, Haddad C, Salameh P, et al. Binge eating, orthorexia nervosa, restrained eating, and quality of life: a population study in Lebanon. Eat Weight Disord. 2021;26(1):145-58. https://doi.org/10.1007/ s40519-019-00831-4.

13. Bohon C. Binge eating disorder in children and adolescents. Child Adolesc Psychiatr Clin N Am. 2019;28(4):549-55. https://doi.org/10.1016/j.chc. 2019.05.003.

14. Stice E. Risk and Maintenance factors for eating pathology: a meta-analytic review. Psychol Bull. 2002. https://doi.org/10.1037/0033-2909.128.5. 825.

15. Goldschmidt AB, Wall MM, Loth KA, Bucchianeri MM, Neumark-Sztainer $D$. The course of binge eating from adolescence to young adulthood. Health Psychol. 2014;33(5):457-60. https://doi.org/10.1037/a0033508.

16. Grilo CM, Masheb RM. Correlates of body image dissatisfaction in treatment-seeking men and women with binge eating disorder. Int J Eat Disord. 2005;38(2):162-6. https://doi.org/10.1002/eat.20162.

17. Rohde P, Stice E, Marti CN. Development and predictive effects of eating disorder risk factors during adolescence: implications for prevention efforts. Int J Eat Disord. 2015;48(2):187-98. https://doi.org/10.1002/eat. 22270.

18. Kessler RC, Berglund PA, Chiu WT, et al. The prevalence and correlates of binge eating disorder in the World Health Organization World Mental Health Surveys. Biol Psychiatry. 2013;73(9):904-14. https://doi.org/10. 1016/j.biopsych.2012.11.020.

19. Self-Report Method |Encyclopedia.com. https://www.encyclopedia. com/social-sciences/applied-and-social-sciences-magazines/self-reportmethod. Accessed 14 Aug 2021

20. Gormally J, Black S, Daston S, Rardin D. The assessment of binge eating severity among obese persons. Addict Behav. 1982;7(1):47-55. https:// doi.org/10.1016/0306-4603(82)90024-7.

21. Brunault P, Gaillard P, Ballon N, et al. Validation de la version française de la Binge Eating Scale: étude de sa structure factorielle, de sa consistance interne et de sa validité de construit en population clinique et non clinique. Encephale. 2016;42(5):426-33. https://doi.org/10.1016/j.encep.2016. 02.009 .

22. Dezhkam M, Moloodi R, Mootabi F, Omidvar N. Standardization of the Persian Version of Binge Eating Scale Standardization of the Binge Eating Scale among Iranian Obese Population. 2009;4. https://ijps.tums.ac.ir/ index.php/ijps/article/view/517. Accessed November 22, 2020

23. Duarte C, Pinto-Gouveia J, Ferreira C. Expanding binge eating assessment: validity and screening value of the Binge Eating Scale in women from the general population. Eat Behav. 2015;18:41-7. https://doi.org/10. 1016/j.eatbeh.2015.03.007.
24. Escrivá-Martínez T, Galiana L, Rodríguez-Arias M, Baños RM. The Binge Eating Scale: structural equation competitive models, invariance measurement between sexes, and relationships with food addiction, impulsivity, binge drinking, and body mass index. Front Psychol. 2019;10(Mar):530. https://doi.org/10.3389/fpsyg.2019.00530.

25. Zeidan RK, Haddad C, Hallit R, et al. Validation of the Arabic version of the binge eating scale and correlates of binge eating disorder among a sample of the Lebanese population. J Eat Disord. 2019;7(1):1-13. https://doi.org/10.1186/s40337-019-0270-2.

26. Mhanna M, Azzi R, Hallit S, Obeid S, Soufia M. Validation of the Arabic version of the Teruel Orthorexia Scale (TOS) among Lebanese adolescents. Eat Weight Disord Stud Anorexia, Bulim Obes. 2021;2021(1):1-9. https://doi.org/10.1007/S40519-021-01200-W.

27. Boulos Nakhoul T, Mina A, Soufia M, Obeid S, Hallit S. Restrained eating in Lebanese adolescents: scale validation and correlates. BMC Pediatr. 2021;21(1):1-11. https://doi.org/10.1186/S12887-021-02728-7.

28. Guillemin F, Bombardier C, Beaton D. Cross-cultural adaptation of health-related quality of life measures: literature review and proposed guidelines. J Clin Epidemiol. 1993;46(12):1417-32. https://doi.org/10. 1016/0895-4356(93)90142-N

29. Beaton DE, Bombardier C, Guillemin F, Ferraz MB. Guidelines for the process of cross-cultural adaptation of self-report measures. Spine (Phila Pa 1976). 2000;25(24):3186-91. https://doi.org/10.1097/00007 632-200012150-00014.

30. Melki IS, Beydoun HA, Khogali M, Tamim H, Yunis KA. Household crowding index: a correlate of socioeconomic status and inter-pregnancy spacing in an urban setting. J Epidemiol Community Health. 2004;58(6):476-80. https://doi.org/10.1136/JECH.2003.012690.

31. Hallit S, Haddad C, Hallit R, et al. Validation of the Hamilton Anxiety Rating Scale and State Trait Anxiety Inventory A and B in Arabic among the Lebanese population. Clin Epidemiol Glob Heal. 2020;8(4):1104-9. https://doi.org/10.1016/j.cegh.2020.03.028.

32. Blodgett Salafia EH, Jones ME, Haugen EC, Schaefer MK. Perceptions of the causes of eating disorders: A comparison of individuals with and without eating disorders. J Eat Disord. 2015;3(1):1-10. https://doi.org/ 10.1186/s40337-015-0069-8.

33. Rosenberg M. Society and the adolescent self-image. Princeton: Princeton University Press; 1965. https://doi.org/10.1515/9781400876136.

34. Garner D. Eating Disorder Inventory-2: professional manual. Psychological Assessment Resources; 1991.

35. Sawaya H, Atoui M, Hamadeh A, Zeinoun P, Nahas Z. Adaptation and initial validation of the Patient Health Questionnaire - 9 (PHQ-9) and the Generalized Anxiety Disorder-7 Questionnaire (GAD-7) in an Arabic speaking Lebanese psychiatric outpatient sample. Psychiatry Res. 2016;239:245-52. https://doi.org/10.1016/j.psychres.2016.03.030.

36. Kroenke K, Spitzer RL, Williams JBW. The PHQ-9: validity of a brief depression severity measure. J Gen Intern Med. 2001;16(9):606-13. https://doi.org/10.1046/j.1525-1497.2001.016009606.x.

37. Hamilton M. The assessment of anxiety states by rating. Br J Med Psychol. 1959;32(1):50-5. https://doi.org/10.1111/j.2044-8341.1959.tb004 67.x.

38. Clark DB, Donovan JE. Reliability and validity of the Hamilton Anxiety Rating Scale in an adolescent sample. J Am Acad Child Adolesc Psychiatry. 1994;33(3):354-60. https://doi.org/10.1097/00004583-19940 3000-00009.

39. Hallit J, Salameh P, Haddad C, et al. Validation of the AUDIT scale and factors associated with alcohol use disorder in adolescents: results of a National Lebanese Study. BMC Pediatr. 2020. https://doi.org/10.1186/ s12887-020-02116-7.

40. Bohn MJ, Babor TF, Kranzler HR. The Alcohol Use Disorders Identification Test (AUDIT): validation of a screening instrument for use in medical settings. J Stud Alcohol. 1995;56(4):423-32. https://doi.org/10.15288/jsa. 1995.56.423.

41. Hallit S, Obeid S, Sacre H, Salameh P. Lebanese Waterpipe Dependence Scale (LWDS-11) validation in a sample of Lebanese adolescents. BMC Public Health. 2021;21(1):1-6. https://doi.org/10.1186/ S12889-021-11662-3.

42. Salameh P, Waked M, Aoun Z. Waterpipe smoking: construction and validation of the Lebanon Waterpipe Dependence Scale (LWDS-11). Nicotine Tob Res. 2008;10(1):149-58. https://doi.org/10.1080/14622200701767753. 
43. Heatherton TF, Kozlowski LT, Frecker RC, Fagerstrom K-O. The Fagerström test for nicotine dependence: a revision of the Fagerstrom Tolerance Questionnaire. Br J Addict. 1991;86(9):1119-27. https://doi.org/10.1111/j. 1360-0443.1991.tb01879.x.

44. Salameh P, Khayat G, Waked M. The Lebanese cigarette dependence (LCD) score: a comprehensive tool for cigarette dependence assessment. Int J Behav Med. 2014;21 (2):385-93. https://doi.org/10.1007/ s12529-012-9288-4.

45. Byrne BM. Structural Equation Modeling with AMOS: Basic Concepts, Applications, and Programming. 2nd ed. London: Taylor and Francis; 2013. https://doi.org/10.4324/9780203805534.

46. Robert SA, Rohana AG, Suehazlyn Z, Maniam T, Azhar SS, Azmi KN. The validation of the malay version of binge eating scale: a comparison with the structured clinical interview for the DSM-IV. J Eat Disord. 2013;1 (1):28. https://doi.org/10.1186/2050-2974-1-28.

47. Rosenvinge JH, Borgen JS, Börresen R. The prevalence and psychological correlates of anorexia nervosa, bulimia nervosa and binge eating among 15-year-old students: a controlled epidemiological study. Eur Eat Disord Rev. 1999;7(5):382-91. https://doi.org/10.1002/(SICI)1099-0968(199911) 7:5\%3c382::AID-ERV309\%3e3.0.CO;2-W.

48. Dikshit R, Karia S, Shah N, Sonavane S, DeSousa A. A study on binge eating behavior in urban adolescents. Asian J Psychiatr. 2020. https://doi. org/10.1016/j.ajp.2020.101998.

49. Zakhour M, Haddad C, Sacre H, Tarabay C, Zeidan RK, Akel M, Hallit R, Kheir N, Obeid S, Salameh P, Hallit S. Differences in the associations between body dissatisfaction and eating outcomes by gender? A Lebanese population study. Rev Epidemiol Sante Publique. 2021;69(3):134-44. https://doi.org/10.1016/J.RESPE.2021.02.003.

50. Swanson SA, Saito N, Borges G, Benjet C, Aguilar-Gaxiola S, MedinaMora ME, Breslau J. Change in binge eating and binge eating disorder associated with migration from Mexico to the U.S. J Psychiatr Res. 2012;46(1):31-7. https://doi.org/10.1016/J.JPSYCHIRES.2011.10.008.

51. Carriere C, Michel G, Féart C, et al. Relationships between emotional disorders, personality dimensions, and binge eating disorder in French obese adolescents. Arch Pediatr. 2019;26(3):138-44. https://doi.org/10. 1016/j.arcped.2019.02.008.

52. Pasold TL, McCracken A, Ward-Begnoche WL. Binge eating in obese adolescents: Emotional and behavioral characteristics and impact on healthrelated quality of life. Clin Child Psychol Psychiatry. 2014;19(2):299-312. https://doi.org/10.1177/1359104513488605.

53. Morgan CM, Yanovski SZ, Nguyen TT, et al. Loss of control over eating, adiposity, and psychopathology in overweight children. Int J Eat Disord. 2002;31(4):430-41. https://doi.org/10.1002/eat.10038.

54. Brechan I, Kvalem IL. Relationship between body dissatisfaction and disordered eating: Mediating role of self-esteem and depression. Eat Behav. 2015;17:49-58. https://doi.org/10.1016/j.eatbeh.2014.12.008.

55. Puccio F, Fuller-Tyszkiewicz M, Ong D, Krug I. A systematic review and meta-analysis on the longitudinal relationship between eating pathology and depression. Int J Eat Disord. 2016;49(5):439-54. https://doi.org/10. 1002/eat.22506.

56. Culbert KM, Racine SE, Klump KL. Research review: what we have learned about the causes of eating disorders-a synthesis of sociocultural, psychological, and biological research. J Child Psychol Psychiatry Allied Discip. 2015;56(11):1141-64. https://doi.org/10.1111/jcpp.12441.

57. Nolen-Hoeksema S, Wisco BE, Lyubomirsky S. Rethinking rumination. Perspect Psychol Sci. 2008;3(5):400-24. https://doi.org/10.1111/j.1745-6924. 2008.00088.x

58. Puccio F, Fuller-Tyszkiewicz M, Buck K, Krug I. Negative urgency and the dual pathway model of bulimic symptoms: a longitudinal analysis. Eur Eat Disord Rev. 2019;27(1):34-48. https://doi.org/10.1002/erv.2647.

59. Hilbert A, Herpertz S, Kersting A, Pietrowsky R, Tuschen-Caffier B, Vocks S. Binge-Eating-Störung. In: S3-Leitlinie Diagnostik Und Behandlung Der Essstörungen. Springer. Berlin. 2019:275-302. https://doi.org/10.1007/ 978-3-662-59606-7_6

60. Rahme C, Obeid S, Sacre H, Haddad C, Hallit R, Salameh P, Hallit S. Emotional eating among Lebanese adults: scale validation, prevalence and correlates. Eat Weight Disord. 2021;26(4):1069-78. https://doi.org/10. 1007/S40519-020-01001-7.

61. Saade S, Hallit S, Haddad C, Hallit R, Akel M, Honein K, Akiki M, Kheir $\mathrm{N}$, Obeid S. Factors associated with restrained eating and validation of the Arabic version of the restrained eating scale among an adult representative sample of the Lebanese population: a crosssectional study. J Eat Disord. 2019;17(7):24. https://doi.org/10.1186/ s40337-019-0254-2.

62. Hrabosky Jl, Masheb RM, White MA, Grilo CM. Overvaluation of shape and weight in binge eating disorder. J Consult Clin Psychol. 2007;75(1):17580. https://doi.org/10.1037/0022-006X.75.1.175.

63. Barry DT, Grilo CM, Masheb RM. Comparison of patients with bulimia nervosa, obese patients with binge eating disorder, and nonobese patients with Binge Eating Disorder. J Nerv Ment Dis. 2003;191(9):589-94. https:// doi.org/10.1097/01.nmd.0000087185.95446.65.

64. Fairburn CG, Cooper Z, Shafran R. Cognitive behaviour therapy for eating disorders: a "transdiagnostic" theory and treatment. Behav Res Ther. 2003;41 (5):509-28. https://doi.org/10.1016/S0005-7967(02)00088-8.

65. Fairburn CG, Harrison PJ. Eating disorders. Lancet. 2003;361:407-16. https://doi.org/10.1016/S0140-6736(03)12378-1.

66. Herbozo S, Schaefer LM, Thompson JK. A comparison of eating disorder psychopathology, appearance satisfaction, and self-esteem in overweight and obese women with and without binge eating. Eat Behav. 2015;17:86-9. https://doi.org/10.1016/j.eatbeh.2015.01.007.

67. Isnard P, Michel G, Frelut ML, et al. Binge eating and psychopathology in severely obese adolescents. Int J Eat Disord. 2003;34(2):235-43. https:// doi.org/10.1002/eat.10178.

68. Lo Coco G, Salerno L, Bruno V, Caltabiano ML, Ricciardelli LA. Binge eating partially mediates the relationship between body image dissatisfaction and psychological distress in obese treatment seeking individuals. Eat Behav. 2014;15(1):45-8. https://doi.org/10.1016/j.eatbeh.2013.10.006.

69. Calado M, Lameiras M, Sepulveda AR, Rodriguez Y, Carrera MV. The association between exposure to mass media and body dissatisfaction among Spanish adolescents. Women's Health Issues. 2011;21 (5):390-9. https://doi.org/10.1016/j.whi.2011.02.013.

70. Serpell L, Neiderman M, Roberts V, Lask B. The shape- and weight-based self-esteem inventory in adolescent girls with eating disorders and adolescent controls. Psychother Res. 2007;17(3):315-9. https://doi.org/10. 1080/10503300600608173.

71. Lacey JH. Bulimia nervosa, binge eating, and psychogenic vomiting: a controlled treatment study and long term outcome. Br Med J. 1983;286(6378):1609-13. https://doi.org/10.1136/bmj.286.6378.1609.

72. Chiodo J, Latimer PR. Vomiting as a learned weight-control technique in bulimia. J Behav Ther Exp Psychiatry. 1983;14(2):131-5. https://doi.org/10. 1016/0005-7916(83)90030-7.

73. Liou YM, Hsu YW, Ho JF, Lin CH, Hsu WY, Liou TH. Prevalence and correlates of self-induced vomiting as weight-control strategy among adolescents in Taiwan. J Clin Nurs. 2012;21(1-2):11-20. https://doi.org/10. 1111/j.1365-2702.2011.03739.x.

74. Toni G, Berioli MG, Cerquiglini L, et al. Eating disorders and disordered eating symptoms in adolescents with type 1 diabetes. Nutrients. 2017;9(8):1-10. https://doi.org/10.3390/nu9080906.

75. Nagata JM, Garber AK, Tabler JL, Murray SB, Bibbins-Domingo K. Prevalence and correlates of disordered eating behaviors among young adults with overweight or obesity. J Gen Intern Med. 2018;33(8):1337-43. https://doi.org/10.1007/s11606-018-4465-z.

76. Elran-Barak R, Sztainer M, Goldschmidt AB, et al. Dietary restriction behaviors and binge eating in anorexia nervosa, bulimia nervosa and binge eating disorder: trans-diagnostic examination of the restraint model. Eat Behav. 2015;18:192-6. https://doi.org/10.1016/j.eatbeh.2015.05.012.

77. Stice E, Nemeroff C, Shaw HE. Test of the dual pathway model of bulimia nervosa: evidence for dietary restraint and affect regulation mechanisms. J Soc Clin Psychol. 1996;15(3):340-63. https://doi.org/10.1521/jscp.1996. 15.3.340.

78. El Othman R, Touma E, El Othman R, Haddad C, Hallit R, Obeid S, Salameh P, Hallit S. COVID-19 pandemic and mental health in Lebanon: a crosssectional study. Int J Psychiatry Clin Pract. 2021;25(2):152-63. https://doi. org/10.1080/13651501.2021.1879159.

79. Haddad C, Zakhour M, Bou Kheir M, et al. Association between eating behavior and quarantine/confinement stressors during the coronavirus disease 2019 outbreak. J Eat Disord. 2020;8(1):1-12. https://doi.org/10. 1186/S40337-020-00317-0.

80. Baiden P, Mengo C, Boateng GO, Small E. Investigating the association between age at first alcohol use and suicidal ideation among high school students: evidence from the youth risk behavior surveillance system. J Affect Disord. 2019;1(242):60-7. https://doi.org/10.1016/j.jad.2018.08.078. 
81. Obeid S, Haddad C, Salame W, Kheir N, Hallit S. Xenophobic attitudes, behaviors and coping strategies among Lebanese people toward immigrants and refugees. Perspect Psychiatr Care. 2019;55(4):710-7. https:// doi.org/10.1111/PPC.12415.

\section{Publisher's Note}

Springer Nature remains neutral with regard to jurisdictional claims in published maps and institutional affiliations.
Ready to submit your research? Choose BMC and benefit from:

- fast, convenient online submission

- thorough peer review by experienced researchers in your field

- rapid publication on acceptance

- support for research data, including large and complex data types

- gold Open Access which fosters wider collaboration and increased citations

- maximum visibility for your research: over $100 \mathrm{M}$ website views per year

At BMC, research is always in progress.

Learn more biomedcentral.com/submissions 